\title{
Are Bullet Riders at Risk of Noise Induced Hearing Impairment?
}

\section{Himanshu KS* and Mohit SG \\ Department of Audiology and Speech Language Pathology, Amity University, India}

*Corresponding author: Himanshu Kumar Sanju, Department of Audiology and Speech Language Pathology, Amity Medical School, Amity University Haryana, Gurgaon, India, Tel: +91-8447353649; E-mail: himanshusanjuaiish@gmail.com

\section{Research Article}

Volume 3 Issue 1

Received Date: March 27, 2018

Published Date: April 09, 2018

DOI: $10.23880 /$ ooaj-16000166

\section{Abstract}

High intensity of noise generated by bullet can cause noise induced hearing loss among regular bullet riders. There is no literature till date investigated noise induced hearing loss among bullet riders. The present study aimed to investigate self-assessment of noise induced hearing impairment among bullet riders. The present study recruit 80 bullet drivers (young adults and middle aged) riding bullet regularly from 5 to 8 years. There were 15 questions related to selfassessment of hearing quality, annoyance evaluation, noise-related attitude, and knowledge adopted from similar studies. The outcome of present questionnaire-based study showed that bullet riders are at risk of noise induced hearing loss. The current study also revealed annoyance among bullet riders and lack of awareness about hearing protection devices.

Keywords: Bullet Riders; Noise; NIHL; Annoyance

Abbreviations: NIHL: Noise Induced Hearing Loss.

\section{Introduction}

It is well evidenced fact that noise exposure for longer duration on regular basis can cause noise induced hearing loss (NIHL). Noise is associated with many psychological problems that can contribute stress [1]. The adverse effect of noise on auditory (damage of hearing) and nonauditory effects such as impulsive behavior, depression, fatigue, poor concentration is well documented in previous literature [2]. Earlier literature reported different population at risk of noise induced hearing impairment includes traffic police, bus drivers, musicians, tractor drivers, railway workers, truck drivers and factory workers [3-5].

\section{Need for the Study}

Previous literature showed different populations at risk of noise induced hearing impairment [3-5]. Nowadays, bullet riding is more fascinating among youths and middle aged. High intensity of noise generated by bullet can cause noise induced hearing loss among regular bullet riders. There is no literature till date investigated noise induced hearing loss among bullet riders. There is need to study self-assessment of noise induced hearing impairment, knowledge and attitude toward harmful 


\section{Otolaryngology Open Access Journal}

consequences of bullet noise, awareness about ear protection devices and annoyance among bullet riders.

\section{Aim of the Study}

The present study aimed to study self-assessment of noise induced hearing impairment among bullet riders.

\section{Methods}

The present study recruit 80 bullet drivers in the age range of 25 to 40 years (young adults and middle aged) from Royal Enfield Motorcycle Club, Delhi-NCR. Informed written consent was taken from all participants of the study. All the participants were regular bullet riders from 5 to 8 years and many had installed external device to increase bullet noise. All the participants were riding bullet $18-25 \mathrm{~km}$ daily. The participants with history of any otological disorders were excluded from the study. The participants with the habit of smoking or drug addiction were excluded from the present study. There were 15 questions related to self-assessment of hearing quality, annoyance evaluation, noise-related attitude, and knowledge adopted from similar studies [3]. The questions directed were in accordance with ISO/TS 15666 (2003), an international standard of acousticsassessment of noise annoyance using social and socioacoustic surveys. The questionnaire was used for the bullet riders under close direction of two audiologists having master degree in audiology. The questions were closed set task with 2 point (yes/no), 3 point (yes/sometime/never) and 4 point rating scale (excellent/above average/average/below average) depend on the nature of question. The questions for selfassessment of hearing quality includes 'quality of hearing', 'hearing over phone', 'hearing in crowd', 'talking too loudly', 'tinnitus/ringing sensation in the ear', 'feeling uncomfortable on loud sound'. The questions for annoyance evaluation includes 'annoyance from bullet noise', 'irritation after drive', 'headache' and 'quality of sleep'. The questions for noise related attitude and awareness regarding ear protection device includes 'ever used earplug or earmuff while driving', 'do these ear protection device effective if used', 'do you know that noise (bullet noise) can cause health problem'. The percentages and proportions of different categories of questionnaires were used to analyze the data.

\section{Results and Discussion}

The data were analyzed along with descriptive statistics, percentages and proportions of the study subjects, in context to a response. All the subjects participated in present study provided response for all the questions. In the current study, only $12 \%$ of the participants reported their hearing as excellent, where as $29 \%$ of the participants reported as above average and $50 \%$ as average. $45 \%$ of the participants miss some conversation while talking over phone. Similarly, $44 \%$ of the participants miss some conversation in crowd. The finding of the present study showed that $44 \%$ of the bullet riders keeps the volume of TV louder. Similarly, $44 \%$ of the bullet riders talks loudly. For the question 'tinnitus/ringing sensation in ear', $30 \%$ of the participants reported yes. The result of the current study revealed that $75 \%$ of the bullet riders feels uncomfortable on loud sounds. Karimi, et al. [6] in 2010 also reported similar outcome among truck drivers [6]. Present data indicates that bullet riders are at risk of noise induced hearing loss and good percentage of the population already showed symptoms of noise induced hearing loss.

Annoyance evaluation revealed that only $30 \%$ of the participants reported excellent sleep, whereas, $70 \%$ of the participants reported poor quality of sleep. $80 \%$ of the participants reported frequent headache, whereas, $70 \%$ of the participants reported annoyance from bullet noise. Similarly, $60 \%$ of the participants reported irritation after drive. The result of the present study showed annoyance among bullet riders with poor quality of sleep. Similar finding was seen in the study of Sanju \& Kumar [3], investigated annoyance among traffic police and bus drivers [3]. Questions related to noise-related attitude, and knowledge about hearing protection devices revealed that $87 \%$ of the bullet riders were unaware from the usefulness of hearing protection devices. Present study also indicates that $92 \%$ of the bullet riders have never used any ear protection devices. Sanju \& Kumar in 2016 also reported poor knowledge about hearing protection devices among bus drivers [3]. Present study revealed an urgent need of regular audiological evaluation among bullet riders. Current study also highlights the importance of awareness regarding noise induced hearing loss among bullet riders. The present investigation also showed the need to aware bullet riders regarding ear protection devices.

\section{Summary and Conclusion}

The outcome of present questionnaire based study showed that bullet riders are at risk of noise induced hearing loss. The current study also revealed annoyance among bullet riders and lack of awareness about hearing protection devices. 


\section{Otolaryngology Open Access Journal}

\section{References}

1. Goines L, Hagler L (2007) Noise pollution: a modern plague. South Med J 100(3): 287-294.

2. Bluhm GL, Berglind N, Nordling E, Rosenlund $\mathrm{M}$ (2007) Road traffic noise and hypertension. Occup Environ Med 64(2): 122-126.

3. Sanju HK, Kumar P (2016) Self-assessment of noiseinduced hearing impairment in traffic police and bus drivers: Questionnaire-based study. Indian Journal of Otology 22(3): 162-167.
4. Lie A, Skogstad M, Johannessen HA, Tynes T, Mehlum IS, et al. (2016) Occupational noise exposure and hearing: a systematic review. Int Arch Occup Environ Health 89(3): 351-372.

5. Alizadeh A, Etemadinezhad S, Charati JY, Mohamadiyan M (2016) Noise-induced hearing loss in bus and truck drivers in Mazandaran province, 2011. Int J Occup Saf Ergon 22(2): 193-198.

6. Karimi A, Nasiri S, Kazerooni FK, Oliaei M (2010) Noise induced hearing loss risk assessment in truck drivers. Noise Health 12(46): 49-55. 